\title{
More about the same: children's understanding of post-articles*
}

\author{
ANNETTE KARMILOFF-SMITH \\ University of Geneva
}

(Received I August 1976)

ABSTRACT

An experiment on children between $2 ; 0$ and $7 ; 0$ showed that they initially interpret the same $X$ to mean 'same kind' in contexts where it actually means 'same one'. This led to a critical evaluation of Piaget's implicit contention that young children are using determiners anaphorically. Stress is placed on the linguistic rather than conceptual component of children's behaviour in experiments involving questions of the type: Is it the same $X$ ? It is argued that language is not only the tool of intelligence for representing ongoing cognitive development, but that it is also a problem area for children within its own right. It is suggested that the importance of young children's processing procedures on the linguistic environment has hitherto been underestimated in Piaget's interactive epistemology.

\section{INTRODUCTION}

'(J. at $2 ; 6)$ That's not a bee, it's a bumble bee. Is it an animal?. But also at about $2 ; 6$ she used the term the slug for the slugs we went to see every morning along a certain road. At $2 ; 7$ she cried: There it is! on seeing one, and when we saw another ten yards further on she cried: There's the slug again. I answered, But isn't it another?. J. went back to see the first one. Is it the same? Yes. Another slug? Yes. Another or the same?...The question obviously had no meaning for J.'

It is not difficult to guess that this is a passage from one of Piaget's early books (1946; see 1951 : 225) and, interestingly enough, it is an example to which he seems attached (Piaget, Sinclair \& Vinh Bang 1968: 127). However, those conversant with Piaget's rich analyses of child behaviour may have found the last sentence above rather atypical. Did the question really have no meaning for J?

["] Our appreciation is extended to the staff and pupils of Pinchat Infants' and Primary School, Geneva, and to the Crèches Communales of Pinchat and Meyrin, Geneva, for welcoming us into their schools. Warm thanks are extended to E. Dekkers, M.-Ch. Fabricé, E. Frankel, I. Ott, G. Robert and M. B. Tra for their assistance in data collection, and to Paul Mengal for his assistance in performing the statistical analyses. 
Within a wide range of experiments designed to study the plurifunctionality of determiners in child language (Karmiloff-Smith 1976 ), one was carried out to analyse young children's comprehension of the words other and same, used anaphorically as post-articles giving emphasis to the so-called contrast between the indefinite and definite articles, $a$ and the. This was completed by a further experiment on production tasks involving equivalent problems.

First let us briefly look at the articles themselves. A few authors have studied children's differential use and understanding of the definite and indefinite articles (Bresson, Bouvier, Damequin, Depreux, Hardy \& Platone 1970, Maratsos 1976, Warden 1973, 1976). The results of their experiments and the conclusions they draw are not, however, mutually reinforcing. Bresson et al. (1970) looked at production tasks, with a population covering a narrow range of four- and fiveyear-olds, where the definite/indefinite distinction depended on the extralinguistic context. They confirm that their subjects had no difficulties in producing the indefinite article when naming objects. However, the authors show that when the problem involved using the indefinite article for referring to one member of a class of identical objects in response to E's question Qui est parti?, the success rate of four-year-olds was under $50 \%$ of total replies and the figure dropped to $3 \mathrm{I} \%$ in the case of five-year-olds. In their interpretation of these findings, Bresson et al. link the difficulties in the use of the non-specific reference to the child's ongoing cognitive problems in class and relation concepts (Piaget \& Inhelder 1959).

Maratsos (1976) studied the use and understanding of articles in various linguistic and extra-linguistic contexts, again only covering two age groups, three- and four-year-olds. In his far-reaching conclusions, he states that, as early as $3 ; 0$, children 'obviously produce indefinite NPs to refer GENERICALLY or to refer to ANY MEMBER OF A CLASS (our emphasis) in contrast to producing definite NPs in minimally contrastive situations where a particular referent had been established for them'. This finding seems to lend support to Brown's naturalistic data on three children studied longitudinally. He suggests that 'children somewhere between the ages of 32 and 41 months, roughly three years, do control the specific/non-specific distinction as coded by the articles' (Brown $1973: 355$ ). Brown none the less adds the proviso that this early productive control of the article contrast does not yet cover instances where the child is obliged to take into account his listener's knowledge.

It is this latter aspect of the use of articles and the role of context on which Warden (1973, 1976) mainly concentrated in an interesting study, developmentally far more extensive than the previous ones mentioned. Contrary to Maratsos, Warden concludes from his data that for children under $5 ; 0$, referring expressions are predominantly definite; that there is inconsistent usage between $5 ; 0$ and $9 ; 0 ;$ and full mastery of the indefinite non-specific reference only from $9 ; 0$. His explanation resides principally in the child's general cognitive progress 
from egocentric to non-egocentric perspectives, and on the problem of the dual function of the indefinite article.

A number of my experiments on French-speaking children between 3;0 and I2; O tally with Warden's results on English-speaking subjects. It is none the less difficult to pin down full mastery of the various functions of both definite and indefinite NPs to any one sphere of cognitive development or to any specific age group. A whole network of general cognitive and specifically linguistic factors appears to be interrelated. Very much depends on the context of the utterance, as Warden suggests, but also on whether the articles appear in isolated sentences or in connected discourse, on the type and tense of the verb, on the way in which $E$ formulates his questions, ${ }^{1}$ on the POTENTIAL size of the class membership various objects/animals may have within the child's world knowledge (e.g. marbles versus A wrist-watch) rather than the ACTUAL size of the class membership in the experimental setting, on topicalization and pre-suppositional interaction between speaker and hearer, as well as on the child's gradual use and understanding of other functions determiners may have. Children do endeavour to make clear reference, but they do not rely on the articles for this (Karmiloff-Smith 1976). The definite/indefinite articles do not seem to be contrastive terms for the young child. The picture of the plurifunctionality of determiners is a highly complex one both linguistically and cognitively, which a narrow age span, or concentration on the articles to the exclusion of other means language offers for making reference, may only partially bring forth.

Much of the experimental work in the field of determiners has been concentrated on production tasks. Comprehension tasks, where they have been used, often gave rise to unsatisfactory results or were based on highly unnatural experimental items which, as Brown (1973) put it, 'place a somewhat unusual communication burden' on the indefinite article. Maratsos (1976), for instance, devised a series of comprehension tasks based on the following model: ' $\mathrm{X}$ acted on one of the Ys... suddenly (the/a) Y performed another action'. 'The $Y$ ' entailed that the child act on the SAME $Y$ as the one in the initial NP, ' $a \mathrm{Y}$ ' entailing that he act on one of the OTHER Ys present. Warden (1973) used a somewhat similar design within an extra-linguistic context. He presented children with pairs of pictures containing three identical Xs and one $\mathrm{X}$ odd-man-out (e.g. different colour, different hat, etc.). Instructions were 'Show me A (nonsense modifer) $\mathrm{X}$ ' which entailed pointing to any one of the identical $\mathrm{Xs}$, or 'Show me THE (nonsense modifier) $X^{\prime}$ ', implying the one that was the only member of its sub-class. The interesting results of these two studies none the less raise an important question. When we experiment in language, particularly when we place

[r] Such differences as Who did it?/What did I hide? implying a simple NP response, as compared to the more neutral What happened?, implying a full sentence, gave rise to different article usage in young subjects. 
unusual communicative burdens on certain morphemes, are we observing the child's normal language-processing procedures or are we observing ad hoc experiment-generated procedures? Such criticism can, of course, be levelled at aspects of my own work. Indeed, it can be shown that the procedures children use for isolated sets of sentences are not necessarily the same as those used when analogous stimuli are inserted into connected discourse (Karmiloff-Smith 1976). In the particular area of articles, semantic distinctions of the type mentioned in the above two experiments would not, in my view, be made solely on the article distinction in natural language usage, but rather by adding contrastive expressions such as the same $X$, another $X$, the only $X$, one of the $X s$, or by other means such as intonational stress, pronominalization, and so forth. The production task was designed to look at how children organize the various linguistic means for making such contrasts, and whether they place the semantic burden on the article contrast alone.

Since the experimental tasks were carried out on French-speaking children, it may be useful to indicate briefly where French and English differ slightly in their use of the words même and same. Clearly there are many intricate nuances of meaning which cannot be developed in this article, where we shall merely stress one or two points.

If a French-speaking child discovers an object similar to one he possesses, he might exclaim: $j$ 'ai le même (meaning literally 'I've got the same'), or $j$ 'ai la même if the name of the object has feminine gender. The more logical but less usual expression would be $j$ 'en ai un même (literally, 'I've of them a same'). An English-speaking child in similar circumstances would be likely to say something like I've got one the same. In both languages, however, same/même has two functions: the descriptor function meaning 'same kind', i.e. members of the same class (e.g. Fane is wearing the same dress as Mary), and the determiner function meaning 'same one', i.e. the same element within a class (e.g. Fane is wearing the same dress as yesterday). There are of course cases which are ambiguous (e.g. $H e$ is using the same argument as last year), but this is often disambiguated by adding such expressions as practically the same or exactly the same. Both English and French are similar in their anaphoric uses of same/meme in sentences of the following type: une limace. . .et la même limace... / a slug . . and the same slug... (clearly meaning 'same one'), as contrasted to ...et une autre limace/... and another slug (meaning 'another one').

The hypothesis that ensues is that if, as Maratsos (1976) maintains, the small child is capable of distinguishing the specific/non-specific reference solely on the differences between two unaccentuated morphemes (the articles), then it should be even easier for such a contrast to be understood if the articles' meanings are emphasized by the addition of the post-articles same and other. Although it remains to be seen what their real functions are in early child language, the 
words same, other, and the articles do all appear very early in corpora (Guillaume 1927, Warden 1973, Brown 1973, Karmiloff-Smith 1976).

\section{EXPERIMENTAL PROCEDURE}

The contexts were as follows:

(i) completely identical objects (e.g. blue plastic ducks, green toy Volkswagens, etc.);

(ii) objects of the same class differing only in colour (e.g. blue or pink plastic lambs, red or blue toy Fords, etc.);

(iii) objects of the same class but differing by several parameters (e.g. brownwooden-standing cow versus white-plastic-seated cow, small-open-red-sports car versus large-white-saloon car, etc.);

(iv) objects the only members of their class (e.g. a horse, a truck, a toy watch, etc.).

There were six basic situation types using very familiar objects such as the above, together with a girl doll and a boy doll. The child was asked to act out a series of sentences of the following design, where in sentence type $(a)$ the key word is in object position, e.g. the girl pushes an $X$ and then the boy pushes (the same) another) $\mathrm{X}$, and in sentence type $(b)$ the key word is in subject position, e.g. an $\mathrm{X}$ bumps into the girl and then (the same/another) $\mathrm{X}$ bumps into the boy. Examples of task items are as follows (context type $(i)$ ):

\begin{tabular}{lll}
\hline Context & \multicolumn{1}{c}{ E's utterance } & Child's expected response \\
\hline $\begin{array}{c}\text { Identical } \\
\text { objects }\end{array}$ & $\begin{array}{l}\text { (a) The girl pushes a X and then } \\
\text { the boy pushes THE sAME X } \\
\text { (b) An X pushes the girl and then } \\
\text { THE sAME X pushes the boy } \\
\text { (a) The boy pushes an X and then } \\
\text { the girl pushes ANOTHER X } \\
\text { (b) An X pushes the boy and then } \\
\text { ANOTHER X pushes the girl }\end{array}$ & Action on one X \\
\hline
\end{tabular}

Context types (ii) $-(i v)$ followed exactly the same pattern.

Simple sentences (e.g. the ducks fall off the table) were interspersed amongst test sentences as fillers to avoid lack of concentration due to somewhat repetitious forms. Whenever necessary, test sentences were repeated. Although certain basic items were presented to all children, we also used the Genevan exploratory method to analyse responses in more depth. This method involves constantly forming hypotheses regarding the reason for a child's response and not merely recording responses. Hypotheses were tested on the spot by, say, placing intonational stress on the post-articles, by reducing or increasing the number and type of objects present at one time, by adding such expressions as the same $X$ as 
the boy just pushed, by using somewhat unusual forms such as a same $X$, by encouraging children to talk about similar objects they possessed, and so forth. ${ }^{2}$ Emphasis was less on success or failure to interpret the same $X$ as 'same one' but on the functions such expressions may be playing at a given level and on how transitions take place. Only the basic items were included in the quantitative analysis of the results; the exploratory part of the experiment provided revealing clues for the qualitative analysis.

The comprehension task involved 47 children between the ages of 2 ; Io and 7 ; II. These children were not selected at random but from the results of two previous experiments on gender acquisition where they had proved to be typical of their age group. Any linguistically very advanced three-year-old, for example, was not included. However, results can either be grouped by age, as in the present case because of pre-selection, or can be grouped according to response patterns where overlapping of ages occurs. In the results, stress is not placed on the actual AGES of the different interpretations, but rather the ORDER of change from one interpretation to the other. Within each sub-collection of items, each child's behaviour was very consistent.

The production task had a similar contextual design to the comprehension task, except that $E$ acted out with toys and asked children to describe the actions to a second experimenter. This was conducted on another, randomly selected group of $6 \mathrm{r}$ subjects between $3 ; 0$ and $\mathrm{I} I ; \mathrm{I}$.

\section{RESULTS}

This paper will mainly confine itself to the results of the comprehension task. In the discussion, however, reference will be made to aspects of the results of the production task (to be reported at length elsewhere) when they are particularly relevant to the interpretation of the comprehension task results.

Table I gives a summary of the comprehension task results, expressed as a precentage of the total number of responses to basic items per situation type for each age group. This is expressed in percentages to facilitate comparisons, although of course the calculations of statistical significance levels were made on the actual frequencies. No distinction has been made between the subject and object positions of the post-articles (sentence types $(a)$ and $(b)$ ), the difference in the results being insignificant, although very slightly in favour of correct 'same one' responses first occurring for same in object position. ${ }^{3}$

It should be noted that the columns labelled 'hesitations' represent the

[2] We had purposely bought our experimental toys in a popular local supermarket in the hope that children might make spontaneous utterances about analogous objects they possessed.

[3] Here, and throughout the following discussion, we cite the English forms same, other, etc. although their French counterparts were of course used in the test. 
CHILDREN'S UNDERSTANDING OF POST-ARTICLES

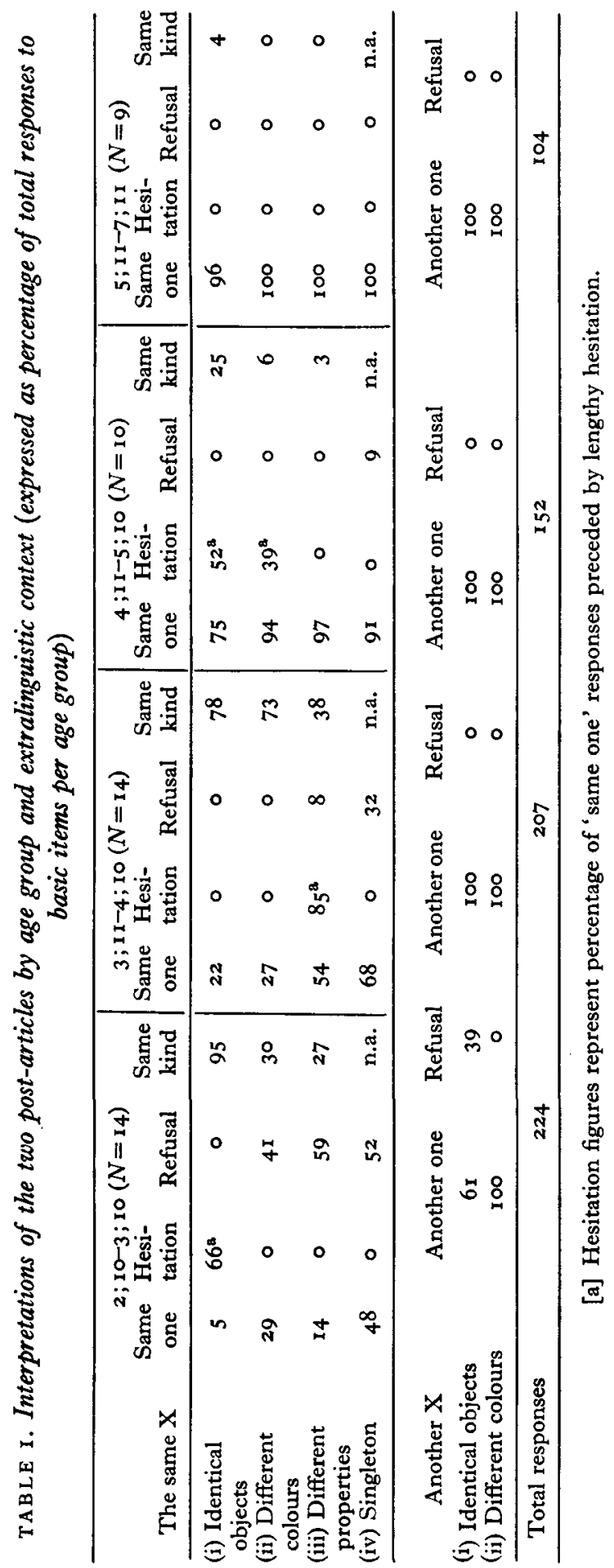


percentage of the 'same one' responses (previous column) which were clearly preceded by lengthy hesitations not apparent elsewhere in the child's behaviour. This table is intended to give a picture of the overall trend. It is in fact more the qualitative analysis of the results, incorporating children's spontaneous utterances, that is more revealing as to the functions same and other have for young children.

From a quantitative point of view, the results show that order of change of interpretation from 'same kind ' to 'same one' is very significantly a function of age (i.e. development) and of the extralinguistic context within each age group $\left(\chi^{2}=424 \cdot\right.$, d.f. $=$ I $\left.2, P<0.00 \mathrm{r}\right)$.

The initial comprehension procedure (i.e. until around $5 ; 0$ ) is to interpret the same $X$ as meaning another $\mathrm{X}$ with the same attributes and not as meaning one and the same $X$. Only if attributes differ considerably does the young child gradually interpret the same $X$ to mean 'same one'. A different picture emerges from the situations in which sentences contain another $X$, although something of the pattern registered with same is also apparent here. Where class members' attributes differ, all age groups were successful in almost $100 \%$ of instances in interpreting 'another $X$ ' to mean 'another one'. Children over 4; 0 did as well in situations where all Xs were identical. Interestingly enough, where Xs were identical, some three-year-olds tended to interpret another $X$ as meaning 'another kind' rather than 'another one' and thus refused to act out a number of the sentences referring to identical contexts. In contrast, no refusals were registered with these subjects for sentences containing other when objects differed in colour. What was observed with these three-year-olds for other thus seems rather similar to what took place developmentally with same. In an attempt to track down more about other and the two functions it has, a group of two-yearolds were interviewed; but the data are inconclusive in view of the unsuitability of the comprehension task with such small children. It is none the less interesting to note that, although concerned with somewhat different problems, Donaldson \& Wales (1970) showed that small children first interpret the word different to mean 'different kind' rather than 'different one', which tallies with what is suggested by our results on three-year-olds regarding other used anaphorically. As pointed out by Clark (1970), the technique used by the above authors did not allow for verification of the child's possible alternative interpretation of same. However, Donaldson \& Wales' results on different, used exophorically for direct reference to the extralinguistic situation, point to very similar general developmental trends compared to the present results on same and other used anaphorically.

Let us now take a more qualitative look at the results for each age group. As was seen in the table, three-year-olds interpret same to mean 'same kind' and act out test sentences of the type the boy pushed a cow and then the girl pushed the same cow by touching Two identical cows, when context permitted, or by frequently refusing to act out if objects were not identical. They persisted in this 
behaviour even if items were repeated and the word same accentuated unnaturally, or if we added expressions such as. . the same cow as the boy just touched. These small children often accompanied their refusals to act out by such comments as: She can't push the same, you didn't put out another cow like that one; There's not the same duck, only a blue one; Which car? That one is not the same. Similar comments were even more numerous when the attributes of class members differed significantly or when there was only one class member. Although the three-yearolds interpreted other correctly provided there was some difference between class members, the $39 \%$ of refusals to items containing other if Xs were identical is particularly striking. Here, too, children accompanied their refusals to act out the item... and the boy caressed another dog by stating: Which dog? That one? But it's the same; I can't do it, They're all the same; There's not another balloon, They're all green.

To summarize for three-year-olds: same is clearly interpreted as meaning 'same kind' and other is often interpreted as meaning 'other kind'. Both of these expressions seem to be interpreted in their descriptor function, i.e. as modifiers telling the child about class attributes, and not in their determiner function, i.e. as post-articles restricting the extension of a class in discourse (in this case to a singleton).

We turn now to the four-year-olds. It is within this age group that the beginnings of transition were to be witnessed. Although there remained a high percentage of incorrect responses to same in the identical situation, in the more exploratory part of the interviews we were often able to change certain responses to correct ones by stressing the post-article or by adding... same $X$ as the boy just pushed. It will be recalled that this was not possible with most three-yearolds. Correct interpretations ('same one') could also be provoked for some fouryear-olds when we alternated recursively singleton $\mathrm{X}$ situations with those containing identical Xs. Comparing four-year-olds to three-year-olds in situations where $X s$ were similar, it can be seen that the percentage of incorrect responses has greatly increased for the older children. This is due to the complete disappearance of refusals to act out. In other words, although same is still interpreted to mean 'same kind', four-year-olds no longer consider it necessary for all attributes to be identical. It was when class members' attributes differed greatly, forming obvious sub-classes for the child, that a significant increase was witnessed in correct 'same one' interpretations; these responses were none the less preceded by lengthy hesitations, as if there was a conflict for the child between the competing interpretations 'same one' and 'same kind'. Another interesting fact occurred occasionally during the exploratory part of the interview. To a question comparing a red plastic duck to a blue plastic duck, some children replied no when asked is it the same? but yes when asked is it the same duck? It may well be that the relations between article, post-article and noun and their respective positions in the NP play an important role in these different 
interpretations, a point to be expanded in the discussion. Items containing other posed no problems whatsoever for four-year-olds.

In summary, four-year-olds clearly interpret other as meaning 'other one', i.e. in its function of post-article determiner, whereas same is still significantly interpreted in its descriptor function meaning 'same kind' and only conflictual situations provoked over $50 \%$ successful 'same one' interpretations.

Five-year-olds registered a very significant change in success rate. They were clearly interpreting same to mean 'same one', although in situations where Xs were identical or similar, many hesitations preceded correct responses, particularly for the first few experimental items. This was not the case with the children over 6 ; o. Thus it can be said that from 5 , but more systematically from 6 , children can interpret both same and other as post-article determiners.

Finally, it is to be noted that while both same and other were successfully interpreted by children over $5 ; 0$, the majority of these children were not successful above chance level in a control experiment to test comprehension of anaphoric the as opposed to $a$ but wITHOUT the addition of same and other. It can therefore be assumed that their interpretation in this experiment is based on the postarticles and not on the articles alone.

\section{DISCUSSION}

How should we interpret these results? Should the burden of explanation be placed on the child's general cognitive development or more specifically on the progress of, say, identity concepts (Piaget $e t$ al. 1968)? Should an explanation be sought in the fact that three-year-olds are particularly concerned with resemblances and differences? Or is there something essentially linguistic at work? How do children cope with flow of linguistic input and the fact that one surface expression may be fulfilling more than one function?

Initially, children seem to prefer to opt for a single function, or if they do use two different functions, these are isolated for the child and he is not aware that they are covered by the same surface marker (Karmiloff-Smith, in the Press). As children begin to notice that one expression may have two or more functions or to introduce relations between isolated existing functions, there is a tendency to overmark a function on several sentence elements (e.g. possessive determiner function overmarked as in mon mien de chapeau à moi) or to create new, and often slightly ungrammatical forms to differentiate the functions. In the present experiment, for instance, there were some revealing differences in the spontaneous utterances of the population. Most three- and four-year-olds, as well as some children at all ages, tended to exclaim: moi j'ai le même (meaning: 'I've got the same') upon seeing one of the task objects. What was interesting, however, was a somewhat ungrammatical form encountered in the experiment only in children over 5 ; $O$ and which bears witness to their attempt to introduce into language 
the distinction that they have made between 'same kind' and same one'. These children when noticing one of the task objects would exclaim: moi $j$ 'ai la même de vache or moi j'ai une de même de vaches (literally: 'I've got the same of cow' or 'I've got one of the same of cows'). Here, they seem to want to express 'same kind' in using la même de or une de même de but at the same time avoid the correct, economic expression la même used by younger children (and by adults for both functions). The children have implicitly understood le même or la même as meaning 'same one' and created a separate expression for 'same kind'. In one of our other experiments on the articles, children made clear distinction in their spontaneous descriptions between $j$ 'ai une vache ('I have $a$ cow'), i.e. the indefinite in its non-specific reference function, and $j$ 'ai une de vache ('I have one cow'), i.e. an ungrammatical form to cover the numeral function."

These very logical yet ungrammatical forms, as well as 'over-marking', tend to disappear once the child implicitly allows for one expression to have more than one function depending on the context of the utterance. However, it should be stressed that the temporary creation of such forms has the very positive function of enabling the child to consolidate and render stable the two separate meanings. If the child were slipping back and forth between the two functions of one surface expression, it would be difficult for him to get a 'grip' on either meaning. The same applies to the way in which the child copes with the physical environment: only by overgeneralizing his 'theories-in-action', by seeking confirmation rather than falsification, can the child master one aspect of the causal relationships and thus be able to recognize counter-examples (Karmiloff-Smith, in the Press). If one were consistantly taking new information into account, or slipping to and fro between competing theories, there would probably be no theories in the first place. The assimilatory function of sensory-motor action schemes can be viewed in a similar way.

Not only the post-articles but also both the definite and indefinite articles have several functions. My other experiments and case studies on determiners indicate that the initially predominant function of the definite article seems to be deictic, i.e. signalling the presence of a singular object or the actions of one salient object extracted from a group of others, within the EXTRALINGUISTIC context. This deictic function of the definite article (sometimes used correctly when the object is alone, and other times incorrectly in the case of non-specific reference) is clearly quite different from an anaphoric INTRALINGUISTIC function. On the other hand, the initially predominant function of the indefinite article appears to be that of giving the NAME of an object, accompanied by a demonstrative or the copula, and not that of non-specific reference. This appears to be borne out by naturalistic data (Bloom 1970) and by Warden's experiments on English-speaking children (Warden 1976).

[4] French does not differentiate between ' $a$ ' and 'one', using for both functions the homonym un (or its feminine counterpart une). 
Bearing in mind these initially predominant functions of the definite and indefinite articles for the three-year-old, let us take another look at 'the slug'! What did J really mean when she exclaimed to Piaget encore la limace and replied affirmatively that it was simultaneously both the same slug and another one (Piaget 1946)? When naming things, $J$ easily and correctly used the indefinite article (e.g. That's not a bee, It's a bumble bee, etc.). It would thus appear that her intention was NOT to give the name of the mollusc, which was already presupposed, shared knowledge between her and her father. Let us translate her utterance as 'again the slug' which is closer to the original French encore la limace, although of course the English book translation ('there's the slug again') is the more colloquial rendering. Encore in French can mean 'again' or 'other'. Encore un biscuit means 'another biscuit'. As mentioned, several investigators have confirmed that young children use a definite referring expression, e.g. the $X$, to refer to any one of a group of objects when it has not yet been made previously salient either extralinguistically or by linguistic reference. In such cases, older children use an indefinite referring expression, e.g. an $X$, one of the $X s$, or a demonstrative that $X$, but not the definite article, which presupposes previous verbal reference or shared implicit referential knowledge. For small children, the definite article clearly seems to be deictic and not anaphoric. They say the slug is crawling on the table even when several other slugs are VISIBLY present. Thus J may have been saying something like 'another the slug', encore referring to class extensional aspects (another one), whereas the definite article, la, was deictic and singled out the mollusc's presence in the extralinguistic context. Indeed, with verbs such as regarder (e.g. 'look at the slug') the use of the definite article is correct. When J walked back to look at the first slug before answering Piaget's question, it is conceivable that she was not checking whether it was the same ONE but rather whether it was the same KIND. Piaget's question may thus have been very meaningful to $J$ in that for the child under 5 ; 0 'another slug' (another one) can indeed be simultaneously 'the same' (same kind).

The point to be stressed - though it merely touches on one aspect of Piaget's rich analyses of sensory-motor and preoperational intelligence - is that neither the definite article in the slug, nor the pronoun in J's exclamation there it is! are necessarily anaphoric. The child's intention in using such terms may initially be predominantly exophoric and deictic, making essentially extralinguistic reference. It only seems anaphoric to the observer who is connecting the child's discourse and interpreting it intralinguistically. It is quite plausible that for the small child there may be one procedure for naming, i.e. copula + indefinite article, and another, quite separate procedure for talking about one object's presence or behaviour, i.e. definite article + verb. It may well be, as suggested by some of our data on gender pronoun reference (Karmiloff-Smith 1975), that young children do not really use anaphora, and that their discourse is not simul- 
taneously connected syntactically and semantically, even though it may appear to be so to the investigator.

Piaget makes a very interesting analysis of J's use of the term the slug. He suggests that the child is looking upon the two slugs, not as different members of the class of slugs, but as successive reappearances of a single member, a sort of semi-individual, semi-generic prototype (Piaget 1946). Although this rich interpretation may reflect conceptual development at some early level, basing the particular hypothesis solely on the child's use of determiners is tenuous, to the extent that the syntactico-semantic FUNCTIONS of expressions in child language do not necessarily coincide with those of adults. The child's use of the definite article may initially be quite devoid of any anaphoric intention and be purely deictic. In another experiment, we noticed that small children frequently accompanied the definite article with pointing gestures, which they did not do when using the indefinite article. Indeed, in many languages the definite article developed diachronically from the demonstrative.

The results of the production experiment concerning actions on same $X$ or on another $X$ clearly show that at all ages children do not place solely on the article contrast, or on a pronoun, the burden of anaphoric reference in contexts where ambiguity of reference might occur. The indefinite article alone is practically never used to convey that a second action took place on another $\mathrm{X}$. Nor is the definite article alone used to convey that a second action took place on the same $\mathrm{X}$ when more than one identical $\mathrm{X}$ is present. In such cases, children attempted to make anaphoric reference by other linguistic marks and even by multiple 'overmarking', e.g. The girl pushed a dog and then also the boy re-pushed again the same dog (instead of the simpler The girl pushed a dog and then the boy pushed the $\mathrm{dog} / \mathrm{it}$ ). The definite article alone was only used in cases of no possible ambiguity of reference, i.e. where only one $\mathrm{X}$ was present, and in such instances it is probable that the definite article is functioning deictically.

The results of the comprehension task showing children's changing interpretation of same necessarily raise questions with respect to the role of language in investigating conceptual progress. Whilst recognizing that certain syntacticosemantic expressions must necessarily be used when experimenting with children, it may be that the verbal component of experiments has played a somewhat more crucial role than Piaget explicitly suggests. It would, for instance, be very difficult to devise experiments to study identity concepts and yet avoid the use of articles and the words same and other. Indeed, when Piaget et al. (1968) studied the problems of the epistemology and psychology of identity, they carried out a series of experiments all of which involved, after spatial rotations, etc. of an object, experimenter-questions of the type: Is it the same drop of water?, Is it the same square?, and so forth. Piaget et al. describe four developmental levels (1968:5) in identity concepts: (i) a tendency to accept identity; (ii) a refusal to accept identity; (iii) acceptance of identity of the object itself but not 
of its quantitative properties; and (iv) a quantitative identity, i.e. conservation.

First of all, it is noteworthy that although the levels (i) and (iii) both accept identity of the object, Piaget suggests that their identical responses have a different cognitive status, based on his overall knowledge of the child's developing concepts. It is, however, the distinction between levels (i) and (ii) which we should like briefly to discuss, as they pertain to the LINGUISTIC component of the tasks. Three- to four-year-olds, when asked Is it the same square? reply in the affirmative. Piaget suggests this is due to their ignoring the transformations involved. Four- to five-year-olds give a negative reply to the same question, because they take the transformations into account. Hence Piaget's two levels. However, if we consider that the expression the same $X$ is interpreted by youngest children as a modifier, and not as a determiner, in situations where there are objects with identical attributes, their affirmative reply could be interpreted to mean 'same kind', i.e. 'ANOTHER square with similar attributes'. For four- to five-year-olds, already interpreting in privileged contexts the same $X$ as a postarticle determiner meaning 'same one', the question will receive a negative reply but also mean 'another square'. Thus, when analysed from the point of view of the functions these expressions have in child language, the opposite replies of the two above groups of children may actually have the same cognitive status of non-identity. The two levels distinguished by Piaget may in fact be one level, since children have understood $E$ 's question in two different ways.

We have seen how cautious Piaget is to avoid misinterpreting the similar responses of two different developmental levels as having the same cognitive status. However, the converse also holds true. Children may be giving different verbal responses which in fact have the same conceptual status. It seems clear that with development children tend to endow linguistic terms such as the same $X$ with different functions, irrespective of the particular conceptual task in which they are being questioned. It is therefore suggested that language is an important experimental variable, a fact that has hitherto been underestimated in Piagetian research.

It still remains to be explained why, in our language experiment, three-yearold children take... and the girl pushes the same cow to mean 'same kind' whereas children over 5 ; o (and adults) all take it to mean 'same one'. We have suggested hypotheses as to why the child opts for one possible meaning rather than the two simultaneously, but not yet why the child chooses 'same kind' rather than 'same one'. In our experiment, there are no spatial rotations, etc. that render the situation conceptually difficult in any way. Indeed, the identity concept involved would be of the most primitive type, i.e. object permanency (Piaget 1936), which is acquired before the onset of language and is considered to be, among other things, a prerequisite for it (Sinclair 1971). It would therefore be difficult 
to interpret the results of the three-year-olds on the basis of conceptual development in identity. Cognitively, it would seem to be equally difficult, if not more so, to make the comparison between two objects and judge them as 'the same' (kind), as to look upon one object as retaining its identity, particularly when no spatial or other transformations have taken place. Is it that the three-year-old is simply more obsessed at this stage of development with similarities of attributes and thus interprets the linguistic expression as referring to this? This may be part of the explanation.

I should, however, like to suggest a more essentially linguistic hypothesis to explain the results. It may be that children are implicitly basing their interpretation 'same kind' on the position of the word same-particularly its relationship to the other words in the NP. This obviously does not mean to imply that there is any EXPLICIT metalinguistic activity dividing words into adult classes of articles, adjectives and nouns! But just as the child generalizes patterns in his physical environment, he does likewise in his linguistic environment (Ervin I964, Klima \& Bellugi 1966), and this may not be merely aimed at expressing semantic intentions. It has been suggested elsewhere that the child's processing procedures on both linguistic and physical environments are very similar (Karmiloff-Smith \& Inhelder 1975). Thus there may be implicit classificatory activity going on in the child's cognitive processing of the linguistic input, linking such words as big, small, yellow, pretty and same, because they occur together in an intonational chunk with article and noun: the big cow, the same cow. This is why it was particularly illustrative to note that when asked to compare one of two ducks to the other, the child replied in the affirmative when asked Is it the same duck? but when asked $I s$ it the same? the reply was negative. It could be that when the question involves same only accompanied by an article, the word same has a different function than when it is inserted between article and noun and looks more like a modifier.

The following trend is hypothesized: first the child makes an NP chunk based on intonational patterns or on something along the lines of Bever's (1970) 'perceptual segmentation'. Then the child breaks down that global chunk into one, two or three slots based on surface structure input patterns: one slot for little words that go with names of things (determiner); one slot for words which tell us about the thing (modifier); and one slot for the name (noun). The modifier slot would be filled with words like big, little, pretty and same. The hypothesis is that the initial choice of interpretation 'same kind' is due to the fact that it matches the classificatory system and the modifier slot position. ${ }^{5}$ Simultaneously the child may frequently confirm his 'theory' in that 'same kind' interpretations

[5] Whilst this is an attractive hypothesis, same does not appear to exhibit all modifier behavioural patterns. As D. Crystal (personal communication) has pointed out, one does not encounter errors of the type samer or samest either in English or in French. However, the absence of such errors does not necessarily weaken the hypothesis in that the very semantics of 'same kind' already implies the comparative. As one child put it... if it's already the same, then it can't be more than that. 
are more consistent in the linguistic input since 'same one' meanings are often replaced by pronominalization, etc. But gradually the actual semantics of the word same would be more clearly developing into the two functions: 'same kind' and 'same one', particularly from instances where the 'same one' meaning is unambiguous. The lengthy hesitations in the transition period and the fact that initial correct responses occur when attributes differ significantly tends to indicate that there may subsequently be a conflict between two competing systems: two semantic functions of same versus its syntactic relations with the other constituents of the NP. The final understanding in this context of same as meaning 'same one' may be considerably helped by the child's more explicit understanding and use of 'other', whereby another $X$ covers the meaning 'same kind' and thus frees same in such circumstances for the meaning 'same one'. Lastly, another important factor is that small children seem to use language exophorically in reference to the extralinguistic context, rather than anaphorically, and this probably also affects the younger child's preferred interpretation of 'same kind'.

Do such young children really develop processing procedures to deal with the patterns and relations observable in the linguistic environment? Are they not confined to communicating their semantic intentions? In his frames model, Minsky (1975) has suggested that " since meaning of utterance is encoded as much in the positional and structural relations between words as in the word choices themselves, there must be processes concerned with analyzing those relations'. A study on the acquisition of the gender opposition in French (Karmiloff-Smith I975) points to the fact that as early as 3 ; o the child creates a phonological procedure to classify noun suffixes and that he can systematically apply this to entirely new nonsense words. It was found that the child bases himself from this very early age on the more formal, phonological aspects of language rather than on the more general cognitive clues (e.g. difference between the sexes in natural gender). This, and the results of the present study, suggest that language is not merely 'the tool of intelligence' for representing ongoing cognitive development (Piaget 1968), but is actually for the child a problem area within its own right.

Suggestions have been made elsewhere (Karmiloff-Smith, in the Press) regarding a tentative model for the interplay of children's conservation-seeking strategies in language acquisition, inspired by Piaget's interactive epistemology and by recent artificial intelligence approaches to language phenomena (e.g. Minsky 1975, Schank 1972). In the previous paper I suggested that children may introduce some of the earliest grammatical markers such as the articles, not for communicative purposes, but FOR THEMSELVES as part of their processing procedures on the linguistic problem area. The use of word order, for instance, conveys semantic intentions. It does not give a separate, stable identity to each constituent of the utterance but a relative one through their ordered relationship. The initial attaching of articles (and perhaps verb inflections) may be 


\section{CHILDREN'S UNDERSTANDING OF POST-ARTICLES}

classificatory in nature and part of child's organization of auditory input. It permits certain predictions about what is to follow and enables the child to classify linguistically in a way which is different to his conceptual distinction between actions and things, in that actions can also be nouns. Cellérier (personal communication) has suggested that repeated RE-PARTITIONING of the same environment (physical, linguistic, etc.) may have a very basic, dynamic function in development generally.

Piaget's epistemology is essentially built on the growing child's logicomathematical interaction with an ever-extending physical environment. It can be argued that Piaget has underestimated the importance of children's constructive interaction with their other environments, such as the linguistic one.

\section{REFERENCES}

Bever, T. G. (1970). The cognitive basis for linguistic structures. In J. R. Hayes (ed.), Cognition and the development of language. New York: Wiley.

Bloom, L. (1970). Language development: form and function in emerging grammars. Cambridge, Mass.: M.I.T.

Bresson, F., Bouvier, N., Damequin, C., Depreux, J., Hardy, M. \& Platone, F. (1970). Quelques aspects du système des déterminants chez des enfants de l'école maternelle: utilisation des articles définis et indéfinis. C.R.E.S.A.S. Bulletin 2. 3-40.

Brown, R. (1973). A first language: the early stages. Cambridge, Mass.: Harvard University Press.

Clark, H. H. (r 970). The primitive nature of children's relational concepts. In J. R. Hayes (ed.), Cognition and the development of language. New York: Wiley.

Donaldson, M. \& Wales, R. J. (1970). On the acquisition of some relational terms. In J. R. Hayes (ed.), Cognition and the development of language. New York: Wiley.

Ervin, S. (1964). Imitation and structural change in children's language. In E. H. Lenneberg (ed.), New directions in the study of language. Cambridge, Mass.: M.I.T.

Guillaume, P. (1927). Le développement des éléments formels dans le langage de l'enfant. Fournal de Psychologie 24. 2 16-29.

Karmiloff-Smith, A. (1975). Can developmental psycholinguistics provide clues to the historical origins of gender? Unpublished manuscript, University of Geneva.

- (1976). Little words mean a lot: the plurifunctionality of determiners in child language. Unpublished Ph.D. thesis, University of Geneva.

- (in the Press). The interplay between syntax, semantics and phonology in language acquisition processes. Proceedings of NATO Conference on the Psychology of Language, Stirling 1976.

Karmiloff-Smith, A. \& Inhelder, B. (1975). If you want to get ahead get a theory. Cognition 3. $195-212$.

Klima, E. S. \& Bellugi, U. (1966). Syntactic regularities in the speech of children. In J. Lyons \& R. J. Wales (eds), Psycholinguistic papers. Edinburgh: University Press.

Maratsos, M. P. (1976). The use of definite and indefinite reference in young children. London: C.U.P.

Minsky, M. (1975). A framework for representing knowledge. In P. A. Winston (ed.), The psychology of computer vision. New York: McGraw-Hill.

Piaget, J. (1936). La naissance de l'intelligence chez l'enfant. Neuchâtel: Delachaux et Niestlé.

— (1946). La formation du symbole chez l'enfant. Neuchâtel: Delachaux et Niestlé. Trans. (195I) as Play, dreams, and imitation in childhood. 


\section{CHILD LANGUAGE}

Piaget,? J. (1968). Le point de vue de Piaget. Fournal international de psychologie. I. $281-99$.

Piaget, J. \& Inhelder, B. (1959). La genèse des structures logiques élémentaires, classifications et sériations. Neuchâtel: Delachaux et Niestlé.

Piaget, J., Sinclair, H. \& Vihn Bang (1968). Epistémologie et psychologie de l'identité. Paris: Presses Universitaires de France.

Schank, R. (1972). Conceptual dependency: a theory of natural language understanding. CogPsych 4. 557-631.

Sinclair, H. (197I). Sensory-motor action patterns as a condition for the acquisition of syntax. In R. Huxley \& E. Ingram (eds), Language acquisition : models and methods. New York: Academic Press.

Warden, D. A. (1973). An experimental investigation into the child's developing use of definite and indefinite reference. Unpublished Ph.D. thesis, University of London.

- (1976). The influence of context on children's use of identifying expressions and reference. BfPsych 67. IoI-12. 